\title{
Digital informed consent on radical prostatectomy surgery - A turning point on patient communication means
}

\author{
Pedro Sousa Passos ${ }^{1,2}$, Nuno Carvalho ${ }^{1}$, Sara Teixeira Anacleto ${ }^{1}$, Mário Cerqueira Alves ${ }^{1}$, \\ Paulo Oliveira Mota 1,3 \\ ${ }^{1}$ Department of Urology, Hospital de Braga, Portugal; \\ ${ }^{2}$ Department of Urology, Hospital de Guimarães, Portugal; \\ ${ }^{3}$ Institute of Life and Health Sciences, University of Minho, Portugal.
}

Submitted 8 June 2021; Accepted 9 July 2021

To the Editor,

Radical Prostatectomy (RP) is one of the preferred treatments for localized prostatic cancer and although surgical complications have been reduced over the years, urinary incontinence and erectile dysfunction are still common and significantly impact the patient's life (1). Therefore, adequate patient education and counselling before RP is essential. Informed Consent (IC) is a crucial element of doctor-patient interaction, and it must ensure that patients receive and understand all the information regarding their diseases and treatments. Implicit in providing IC is assessing the patient's understanding, since accessible communication enables them to make informed decisions consciously and autonomously about their health status $(2,3)$. IC assumes higher relevance in surgery since it comprises invasive procedures, related consequences, and greater anxiety levels from patients (4). Several studies demonstrate that patients' education about their clinical process leads to lower anxiety levels and low existing postoperative complications $(4,5)$. Recent studies showed that animated illustrations, with audio explanations, led to better learning and processing of information, reducing the gap between patients with lower and higher health literacy levels (6). With this preliminary study, we aimed to determine the benefit of a video-based educational tool on the patient's health information compared to a healthcare provider's verbal explanation. We also intend to evaluate the impact of the patient's educational level in this process.

\section{MATERIALS AND METHODS}

\section{Patient population}

Men over 18 years old, with different educational levels and followed at the Urology Department of Hospital de Braga, submitted to a RP, open or laparoscopic, between November and December 2020. There were no exclusion criteria.

\section{Study design}

Presentation of an educational animated video by the health care provider to the study group on the preoperative consultation before getting the IC for the RP. This video contained general information about the procedure: postoperative period, potential complications, and reasons to seek medical help. Representative frames of the video are shown in Figure 1. For this preliminary study, the sample population was randomly divided into two groups: Control Group (verbal explanation before providing the IC) and Study Group (educational animated video before the IC). After the preoperative consultation, each group would answer two questionnaires.

\section{Questionnaires}

We created both questionnaires having as an example, a previous and similar study of the European Association of Urology (Cronbach's alpha coefficient of 0.861) (7). Each questionnaire included: Nine patient satisfaction questions, regarding the contentment about the information they received during the preoperative consultation, and before signing the IC; two multiple-choice knowledge questions, regarding patient-s knowledge about RP.

\section{Statistical analysis}

For analytical purposes, the patient satisfaction answers (Qscore) involved five options: strongly agree (5 points), agree (4 points), I do not know (3 points), disagree ( 2 points) and strongly disagree ( 1 point). The maximum score was 45 points. In the two knowledge questions (Pscore), each patient received one point per corrected item. The variable Pscore was dichotomised, so those who answered none or one correct answer were coded 0 , and those who responded correctly to both questions were coded 1. A similar process was conducted for the variable Educational Level, as patients who studied until the primary educational level were coded 0 and those who studied secondary educational level, or more were coded 1. A p-value $<0.05$ was considered as statistically significant, and the Confidence Interval (CI) used was $95 \%$. 


\section{Figure 1.}

Representative frames of the video presented to the study group before IC.

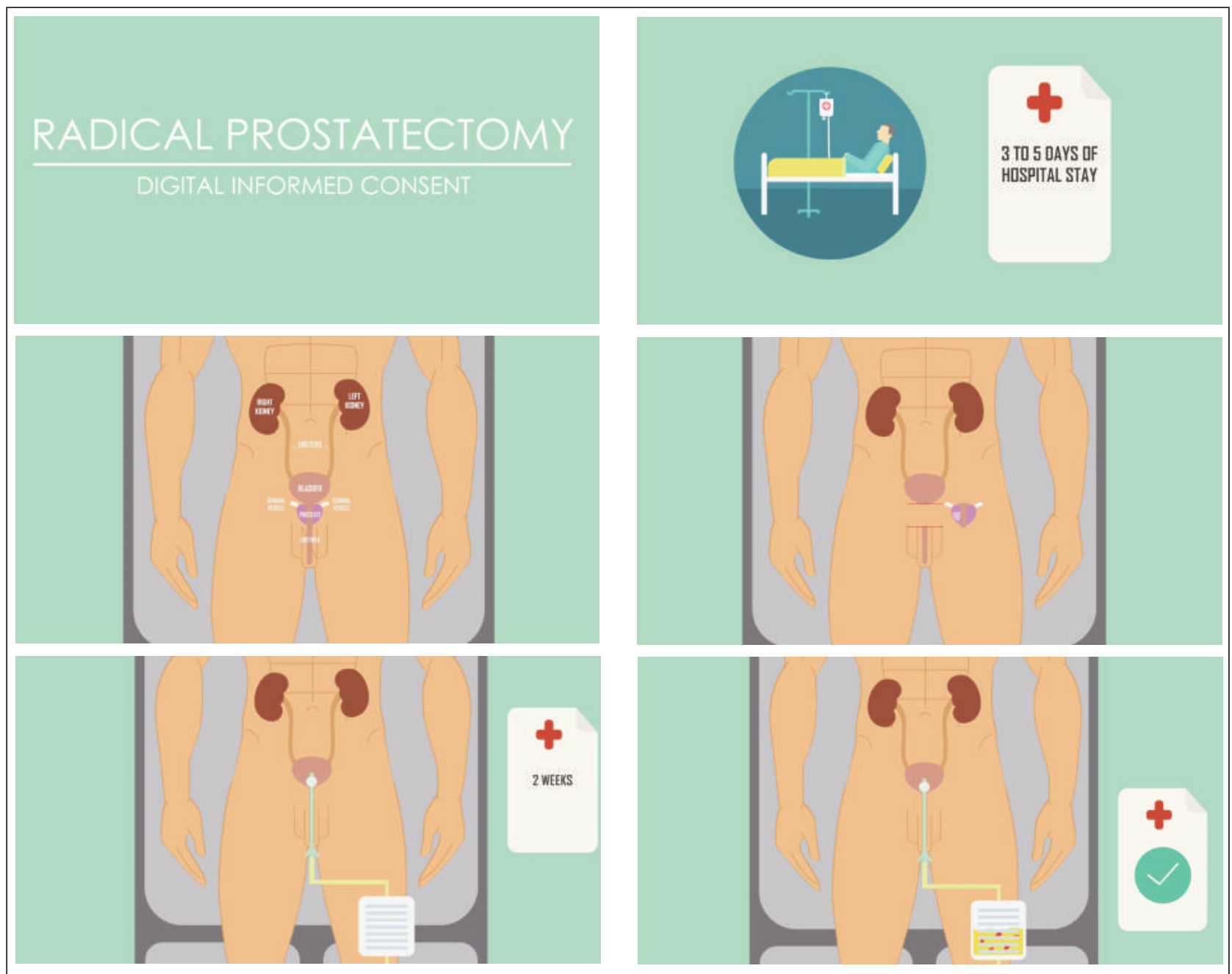

\section{RESULTS}

\section{Sample description}

32 patients were included in this preliminary study, and all subjects completed and returned the questionnaires. The groups were divided in: Control Group: 21 patients, that did not visualise the educational animated video and only received verbal information from their healthcare giver before signing IC; Study Group: 11 patients that visualized the educational animated video before signing IC. As shown in Table 1, most of the participants in both groups had studied until primary education level ( $81.0 \%$ vs $63.6 \%$ ).

\section{Video's impact on patient satisfaction questions}

In this section of the questionnaire and, by comparing the medians of satisfaction scores, we found that patients from the study group presented statistically significantly higher satisfaction levels - QScore $=44.0$ (2.00), than those from the control group - QScore $=32.0(6.00) ; \mathrm{p}<0.001$.

\section{Video's impact on patient knowledge questions}

In this section of the questionnaire and according to the results, we concluded that the study group subjects gave more correct answers than those from the control group.

\section{Educational level's impact on patient satisfaction questions}

We did not find any significant differences on patients' satisfaction questions between patients with "until primary level of education" variable - QScore = 36.0 (11.5) and those with "secondary level of education" - QSCore = 42.0 (15.5); p = 0.326.

\section{Educational level's impact on patient knowledge questions}

Patients with lower educational level failed more questions than those with higher educational level. We performed Fisher's Exact Test, and results showed that Pscore is dependent on educational level $(\mathrm{p}=0.038$; Phi $=.404)$. 
Table 1.

Descriptive statistics of the education level variable in each group.

\begin{tabular}{|l|c|c|c|}
\hline & Until primary educational & Level secondary education or more & Total frequency (n) \\
\hline Control group & $17(81.0 \%)$ & $4(19 \%)$ & 21 \\
\hline Study group & $7(63.6 \%)$ & $4(36.4 \%)$ & 11 \\
\hline
\end{tabular}

\section{Table 2.}

Results of the multiple linear regression for Qscore, to predict patients' satisfaction.

\begin{tabular}{|c|c|c|c|c|c|c|c|}
\hline & \multicolumn{2}{|c|}{$\begin{array}{l}\text { Unstandardised } \\
\text { coefficients }\end{array}$} & \multicolumn{3}{|c|}{$\begin{array}{c}\text { Standardised } \\
\text { coefficients }\end{array}$} & \multicolumn{2}{|c|}{$\begin{array}{c}95 \% \text { Confidence } \\
\text { interval for B }\end{array}$} \\
\hline & B & Std. error & $\beta$ & $t$ & p-value & $\begin{array}{l}\text { Lower } \\
\text { bound }\end{array}$ & $\begin{array}{l}\text { Upper } \\
\text { bound }\end{array}$ \\
\hline Constant & 32.9 & 1.26 & & 26.0 & $<0.001$ & 30.3 & 35.5 \\
\hline Video & 10.8 & 2.06 & 0.708 & 5.24 & $<0.001$ & 6.59 & 15 \\
\hline Educational level & -0.918 & 2.26 & -0.055 & -0.406 & 0.688 & -5.55 & 3.71 \\
\hline
\end{tabular}

\section{Table 3.}

Results of the logistic regression for Pscore.

\begin{tabular}{|l|c|c|c|c|c|c|cc|}
\hline & B & $\begin{array}{c}\text { Std. } \\
\text { error }\end{array}$ & Wald & DF & p-value & $\begin{array}{c}\text { EXP } \\
\text { (B) }\end{array}$ & $\begin{array}{c}\text { 95\% Confidence } \\
\text { interval for B }\end{array}$ \\
\hline & & & & & & & Lower bound & Upper bound \\
\hline Educational level & 2.25 & 1.16 & 3.78 & 1 & 0.052 & 9.47 & 0.98 & 91.2 \\
\hline Video & 3.12 & 1.07 & 8.48 & 1 & 0.004 & 22.7 & 2.78 & 186 \\
\hline (Constant) & -2.10 & 0.75 & 7.79 & 1 & 0.005 & 0.12 & & \\
\hline
\end{tabular}

\section{Patient satisfaction questions predictors}

We performed a multiple linear regression to predict patients' satisfaction using "video visualization" and "educational level" as variables. These were coded as No video visualization $=0$ and Video visualization $=1$; Primary educational level $=0$ and secondary level of education or more $=$ 1. Video visualization was the only statistically significant predictor. Patients who watched the video, from the study group, had 10.8 (95\% CI 6.59 to 15.0) more points than those from the control group, as shown in Table 2 .

\section{Patient knowledge questions predictors}

For patients' knowledge predictors, we performed a binary Logistic Regression and, as presented in Table 3, video visualization was statistically significantly $(p=0.004)$. Pscore was coded as one correct answer $=0$ and two correct answers $=1$. Patients who visualized the video were 3.12 (95\% CI 2.78 to 186 ) times more likely to correctly answer both questions.

\section{Discussion}

Using an educational animated video to communicate health information to patients is associated with higher levels of patients' satisfaction and knowledge about the surgical procedure. This study also suggests that educational level can influence the patient's understanding of health information. Video-based education has shown promising early results. In 2002, Mayer showed that illustrations help create a mental image; therefore, facilitate learning and overlapping text-based learning (8). On their study, Abed et al., using image illustration and due to the video's portability and repeatability, showed that an educational animation can increase patients' understanding and information acquisition and their satisfaction with the health care provided $(9,10)$. In this study, we confirmed that subjects who only received verbal information had wrong ideas about the procedure they were undertaking, reinforcing the need for new alternatives to explain and better inform patients. We verified that we could increase patients' knowledge by showing the educational video since the study group had statistically significantly higher P scores. Although patient's satisfaction scores did not statistically differ amid different education levels, those with higher education levels performed better on knowledge questions. These results meet what the literature suggests. We found that patients who visualized the video scored higher on patient satisfaction and knowledge questions, concluding that accessible information can influence the way patients understand clinical information and eventually, positively impact clinical outcomes $(4,11,12)$.

\section{Conclusions}

Empowering patients with knowledge improves clinical outcomes, patient's compliance and it should be a fundamental philosophy of clinical excellence. Addressing to current times, the COVID-19 pandemic has proven the importance of accurate information and showed the significance of providing people with accessible and correct health information. It is important to enable everyone to make informed decisions and ensure that they can act as a public health agent, which will undeniably positively affect the worldwide population.

\section{References}

1. Daniyal M, Siddiqui ZA, Akram M, et al. Epidemiology, etiology, diagnosis and treatment of prostate cancer. Asian Pac J Cancer Prev. 2014; 15:9575-8.

2. Sousa J, Araújo M, Matos J. Consentimento Informado:Panorama atual em Portugal. Revista Portuguesa de Ortopedia e Traumatologia. 2015; 23:6-17.

3. Osime OC, Okojie O, Osadolor F, Mohammed S. Current practices and medico-legal aspects of preoperative consent. East Afr Med J. 2004; 81:331-335

4. Winter M, Kam J, Nalavenkata S, et al. The use of portable video media vs standard verbal communication in the urological consent process:A multicentre, randomised controlled, crossover trial. BJU International. 2016; 118:823-828.

5. Armstrong AW, Alikhan A, Cheng LS, et al. Portable video media for presenting informed consent and wound care instructions for skin biopsies: A randomised controlled trial. Br J Dermatol. 2010; 163:1014-1019. 
6. Meppelink CS, Van Weert JC, Haven CJ, Smit EG. The effectiveness of health animations in audiences with different health literacy levels: An experimental study. J Med Internet Res. 2015; 17:e11.

7. Bach T, Behrendt M, Tanidir Y, et al. Harnessing new media tools in patient information. Eur Urol. 2018; 74:685-687.

8. Mayer RE. Multimedia learning. Psychology of learning and motivation. Academic Press. 2002; 41:85-139.

9. Wilson EA, Park DC, Curtis LM, et al. Media and memory: The efficacy of video and print materials for promoting patient education about asthma. Patient Educ Counsel. 2010; 80:393-398.

10. Green MJ, Peterson SK, Baker MW, et al. Effect of a computer-based decision aid on knowledge, perceptions, and intentions about genetic testing for breast cancer susceptibility: A randomised controlled trial. JAMA. 2004; 292:442-452.

11. Idriss NZ, Alikhan A, Baba K, Armstrong AW. Online, video-based patient education improves melanoma awareness: A randomised controlled trial. Telemed J E Health. 2009; 15:992-997.

12. Luck A, Pearson S, Maddem G, Hewett P. Effects of video information on pre colonoscopy anxiety and knowledge: A randomised trial. Lancet. 1999; 354:2032-2035.

\section{Correspondence}

Pedro de Sousa Passos, MD

pedrosousapassos@gmail.com

Nuno Carvalho, MD

nunofsc9@gmail.com

Sara Teixeira Anacleto, MD

sara.anacleto241@gmail.com

Mário Cerqueira Alves, MD

mcerqueiraalves@gmail.com

Paulo Oliveira Mota, MD

damota.paulo@gmail.com

Largo Bairro do Jardim 3, 4900-467 Viana do Castelo (Portugal) 